\title{
Seasonal variations in vitamin D status in indoor and outdoor female athletes
}

\author{
ASAKO MARUYAMA-NAGAO ${ }^{1,3}$, KEISHOKU SAKURABA ${ }^{2}$ and YOSHIO SUZUKI ${ }^{2}$ \\ ${ }^{1}$ Department of Health and Sports Science; ${ }^{2}$ Graduate School of Health and Sports Science, Juntendo University, \\ Inzai, Chiba 270-1695; ${ }^{3}$ Department of Host Defense and Biochemical Research, School of Medicine, \\ Juntendo University, Bunkyo-ku, Tokyo 113-8421, Japan
}

Received February 2, 2016; Accepted April 25, 2016

DOI: $10.3892 /$ br.2016.671

\begin{abstract}
Vitamin D (VD) insufficiency is a concern, particularly among young females. The VD status shows seasonal variations, since it correlates with duration of sunlight exposure. VD insufficiency in indoor athletes is therefore suggested in winter. The aim of the present study was to determine seasonal variations in VD and bone status among indoor and outdoor female athletes. The prospective study was conducted in participants aged 20-22 years old. The participants comprised of 15 indoor and 15 outdoor athletes. The biochemical markers and bone parameters were measured in March, June, September and December. The serum 25-hydroxyvitamin D (25-OH-VD) concentration showed a seasonal oscillation, with a nadir in March (indoor, $19 \pm 4.0 \mathrm{ng} / \mathrm{ml}$; outdoor, $32 \pm 2.7 \mathrm{ng} / \mathrm{ml}$ ) and a peak in September (indoor, $32 \pm 6.6 \mathrm{ng} / \mathrm{ml}$; outdoor, $39 \pm 5.7 \mathrm{ng} / \mathrm{ml}$ ). The amplitude of oscillation was greater in the indoor compared to the outdoor athletes. Seasonal variations in serum calcium exhibited a similar pattern, while the parathyroid hormone showed an inverse pattern to serum 25-OH-VD. The nadir in bone mass, measured as speed of sound, occurred in June after peaking in December among the indoor and outdoor athletes. The pattern followed 3 months after the changes in 25-OH-VD. Indoor sports athletes are more susceptible to VD insufficiency compared to outdoor sports athletes. Insufficiency is most likely to arise in winter, and could affect bone mineralization observed 3 months after.
\end{abstract}

Correspondence to: Mrs. Asako Maruyama-Nagao, Department of Health and Sports Science, Juntendo University, 1-1 Hiraga-gakuendai, Inzai, Chiba 270-1695, Japan

E-mail: asmaruya@ juntendo.ac.jp

Key words: vitamin D insufficiency, seasonal change, female athletes, indoor, outdoor

\section{Introduction}

As peak bone mineral density (BMD) is achieved at 20 years old, achieving high peak bone mass early in life is important to minimize the risk of osteoporosis (1). However, vitamin D (VD) insufficiency is a global concern (2), particularly in younger females $(3,4)$. Approximately $90 \%$ of adolescent females are reported to show either deficiency or insufficiency of VD (5).

Physical activity has been noted as important for increasing peak bone mass. Courteix et al (6) recommended high-impact exercises involving jumping movements. Physical activities, including certain competitive sports, increase BMD, and the mechanical stress induced by the physical activity exerts a major influence on bone (7). Ohta et al (8) reported a positive association between physical activity and serum VD levels. However, numerous elite Australian gymnasts are insufficient in VD (9), and the proportion of athletes with insufficient VD is higher among indoor athletes (such as basketball players and dancers) compared to outdoor athletes (such as tennis and soccer players) (10).

Seasonal variations are observed in VD status, with low serum 25-hydroxyvitamin D (25-OH-VD) levels in winter and high levels in summer (11). Therefore, it may be presumed that indoor athletes are more susceptible to VD insufficiency in winter, and that this would adversely affect bone health.

The aim of the present study was to determine seasonal variations in the levels of serum 25-OH-VD and bone turnover markers, as well as the bone status in Japanese female college athletes.

\section{Materials and methods}

Subjects. A total of 30 female college athletes between 20-22 years old were enrolled in the study from the Department of Sports Medicine, Juntendo University (Inzai, Chiba, Japan), including 15 outdoor athletes (soccer players) and 15 indoor athletes (basketball and volleyball players). Participants were provided a thorough explanation of the objectives, methods and ethical considerations of the study and all provided written informed consent to participate. The number of the subjects was set to detect the mean difference of 25-OH-VD at $\mathrm{P}<0.01$ and power of 0.8 with the effect size reported in 
Table I. Characteristics of the participants at baseline $(n=27)$.

\begin{tabular}{|c|c|c|c|c|c|c|c|c|}
\hline \multirow[b]{2}{*}{ Characteristics } & \multicolumn{4}{|c|}{ Outdoor athletes $(n=13)$} & \multicolumn{4}{|c|}{ Indoor athletes $(n=14)$} \\
\hline & Mean \pm SD & Median & Min & Max & Mean \pm SD & Median & Min & Max \\
\hline Age, year & $20.5 \pm 0.5$ & 21 & 20 & 21 & $20.6 \pm 0.6$ & 21 & 20 & 22 \\
\hline Height, cm & $160.3 \pm 5.4$ & 160 & 153 & 170 & $162.6 \pm 3.3$ & 163 & 157 & 169 \\
\hline Weight, kg & $58.3 \pm 4.6$ & 57.5 & 51.3 & 65.3 & $60.0 \pm 4.3$ & 60.1 & 52.6 & 68.8 \\
\hline Body mass index, $\mathrm{kg} / \mathrm{m}^{2}$ & $22.7 \pm 1.6$ & 22.3 & 20.8 & 26.2 & $22.7 \pm 1.3$ & 22.7 & 19.9 & 25.5 \\
\hline Body fat, \% & $25.5 \pm 2.9$ & 24.5 & 21.2 & 31.2 & $25.2 \pm 2.7$ & 26.0 & 19.8 & 29.5 \\
\hline
\end{tabular}

$\mathrm{SD}$, standard deviation.

the previous study by Halliday et al (12). Three participants (1 outdoor and 2 indoor athletes) did not complete the study. Data from the remaining 27 athletes were analyzed. Initial age, height, weight, body mass index and body fat percentage were homogeneous between groups (Table I).

Study design. Participants arrived at the institute (Juntendo University, Inzai, Chiba, Japan) on the morning of a day in March, June, September and December without taking breakfast. Venous blood was collected from the median cubital vein. Participants refrained from exercise for $\geq 24 \mathrm{~h}$ before blood collection. They also completed a questionnaire regarding their physical activities.

All study protocols were reviewed and approved by the ethics committee at Juntendo University School of Health and Sports Science.

Serum biomarkers. Blood biochemical indices were analyzed by SRL clinical laboratory (Tokyo, Japan) using the following reagents and apparatus. Serum 25-OH-VD was measured using 25-hydroxyvitamin D ${ }^{125}$ I radioimmunoassay kit (DiaSorin, Saluggia, Italy). Tartrate-resistant acid phosphatase-5b (TRACP-5b) was assayed using Osteolinks-TRAP-5b (DS Pharma Biomedical, Osaka, Japan). Serum intact parathyroid hormone (PTH) and bone alkaline phosphatase (BAP) were analyzed using electrochemiluminescence immunoassay kits provided by Roche Diagnostics Japan (Tokyo, Japan) and Beckman Coulter, Inc. (Brea, CA, USA), respectively. Serum calcium (Ca) was measured using a Hitachi 7170 chemistry analyzer (Hitachi, Tokyo, Japan).

PTH, 25-OH-VD and serum Ca are measures of bone mineralization. In addition, to examine bone metabolism, BAP was assessed as a bone formation marker, as well as TRACP-5b as a bone absorption marker.

Bone quality. Calcaneal mineral density was assessed using an AOS-100NW ultrasound bone densitometry (Hitachi Aloka Medical, Tokyo, Japan). This system measures two indices: Speed of sound (SOS) and transmission index (TI). SOS is determined as the ultrasonic conduction velocity penetrating the calcaneus. As this velocity depends on the density, a higher SOS indicates higher bone density. TI is an index calculated from the transmitted ultrasound that correlates with bone mass. A higher TI also indicates higher density. A synthetic parameter osteo-sono-assessment index (OSI) is computed from SOS and TI according to the equation OSI $=(\mathrm{SOS})^{2} \mathrm{x}$ TI. OSI correlates closely with BMD measured by dual-energy X-ray absorptiometry (13).

Statistics. Data are presented as mean \pm standard deviation. Seasonal changes in each group were determined using the Friedman test followed by Dunn-Bonferroni post hoc test. The difference in the mean ratio of peak 25-OH-VD in each season was assessed using the Mann-Whitney U test. Statistical analysis was performed using IBM SPSS Statistics version 19 (IBM Japan, Tokyo, Japan). $\mathrm{P}<0.05$ was considered to indicate a statistically significant difference.

\section{Results}

Seasonal changes in 25-OH-VD concentrations. The mean 25-OH-VD concentration was lowest in March and highest in September in the indoor and outdoor athletes: Indoor, $19 \pm 4.0 \mathrm{ng} / \mathrm{ml}$; outdoor, $32 \pm 2.7 \mathrm{ng} / \mathrm{ml}$ in March; and indoor, $32 \pm 6.6 \mathrm{ng} / \mathrm{ml}$; outdoor, 39 $\pm 5.7 \mathrm{ng} / \mathrm{ml}$ in September. Similarly, serum $\mathrm{Ca}$ concentration was higher from June to September compared to December and March in the two groups (Table II).

The serum 25-OH-VD concentrations in all the outdoor athletes remained above the cut-off for insufficiency $(20 \mathrm{ng} / \mathrm{ml})$ all year round, whereas a significant proportion of indoor athletes showed insufficiency in March (9/14, 64.3\%) and December (4/14, 28.6\%) (Fig. 1).

Seasonal changes in serum $\mathrm{Ca}$ and PTH. Seasonal variations in serum $\mathrm{Ca}$ and PTH showed the same and inverse patterns to serum 25-OH-D, respectively (Table II). Although patterns of seasonal variations were similar in the indoor and outdoor athletes, the amplitude of biochemical markers was greater among the indoor athletes in comparison. The mean serum PTH showed statistically significant differences between seasons in the indoor athletes (Table II).

When expressed as a relative value with individual peak concentration between March and December defined as $100 \%$, the mean $25-\mathrm{OH}-\mathrm{VD}$ was significantly lower among indoor athletes compared to outdoor athletes in March and December: $59.4 \pm 11.3$ vs. $79.2 \pm 11.0 \%$ in March; and $73.7 \pm 15.3$ vs. $82.4 \pm 8.4 \%$ in December (Fig. 2). The mean PTH was 
Table II. Biochemical markers and bone parameters in the indoor and outdoor athletes.

\begin{tabular}{|c|c|c|c|c|c|}
\hline Parameters & $\begin{array}{l}\text { Reference } \\
\text { range }\end{array}$ & $\begin{array}{c}\text { March, } \\
\text { mean } \pm \mathrm{SD}\end{array}$ & $\begin{array}{c}\text { June, } \\
\text { mean } \pm \mathrm{SD}\end{array}$ & $\begin{array}{l}\text { September, } \\
\text { mean } \pm \mathrm{SD}\end{array}$ & $\begin{array}{l}\text { December, } \\
\text { mean } \pm \mathrm{SD}\end{array}$ \\
\hline \multicolumn{6}{|c|}{ Outdoor athletes $(n=13)$} \\
\hline 25-OH-VD, ng/ml & $7-41$ & $32 \pm 2.7^{\mathrm{a}}$ & $38 \pm 8.2$ & $39 \pm 5.7^{a, b}$ & $34 \pm 4.0^{\mathrm{b}}$ \\
\hline PTH, pg/ml & $10-65$ & $49 \pm 22$ & $39 \pm 22$ & $37 \pm 16$ & $34 \pm 10$ \\
\hline $\mathrm{Ca}, \mathrm{mg} / \mathrm{ml}$ & $8.2-10.2$ & $9.4 \pm 0.3^{\mathrm{a}}$ & $9.7 \pm 0.3$ & $9.7 \pm 0.2^{\mathrm{a}}$ & $9.6 \pm 0.3$ \\
\hline $\mathrm{BAP}, \mu \mathrm{g} / 1$ & $2.9-14.5$ & $14.7 \pm 4.5^{\mathrm{a}, \mathrm{b}}$ & $13.8 \pm 4.4$ & $13.0 \pm 4.5^{\mathrm{a}}$ & $12.4 \pm 3.0^{\mathrm{b}}$ \\
\hline TRACP-5b, mU/dl & $120-420$ & $346 \pm 107$ & $379 \pm 104$ & $361 \pm 94$ & $365 \pm 83$ \\
\hline $\mathrm{SOS}, \mathrm{m} / \mathrm{sec}$ & & $1,622 \pm 26$ & $1,621 \pm 21^{\mathrm{a}}$ & $1,629 \pm 28$ & $1,639 \pm 31^{\mathrm{a}}$ \\
\hline $\mathrm{TI}$ & & $1.243 \pm 0.102$ & $1.281 \pm 0.09$ & $1.272 \pm 0.092$ & $1.277 \pm 0.106$ \\
\hline OSI, & & $3.274 \pm 0.354$ & $3.37 \pm 0.304$ & $3.384 \pm 0.35$ & $3.439 \pm 0.392$ \\
\hline \multicolumn{6}{|l|}{ Indoor athletes $(n=14)$} \\
\hline 25-OH-VD, ng/ml & $7-41$ & $19 \pm 4.0^{\mathrm{a}-\mathrm{c}}$ & $29 \pm 6.3^{\mathrm{a}}$ & $32 \pm 6.6^{\mathrm{b}}$ & $24 \pm 6.6^{c}$ \\
\hline $\mathrm{PTH}, \mathrm{pg} / \mathrm{ml}$ & $10-65$ & $55 \pm 18^{\mathrm{a}-\mathrm{c}}$ & $35 \pm 10^{\mathrm{a}}$ & $39 \pm 12^{b}$ & $33 \pm 11^{\mathrm{c}}$ \\
\hline $\mathrm{Ca}, \mathrm{mg} / \mathrm{ml}$ & $8.2-10.2$ & $9.2 \pm 0.3^{\mathrm{a}-\mathrm{c}}$ & $9.7 \pm 0.2^{\mathrm{a}}$ & $9.6 \pm 0.3^{b}$ & $9.5 \pm 0.3^{c}$ \\
\hline $\mathrm{BAP}, \mu \mathrm{g} / 1$ & $2.9-14.5$ & $15.4 \pm 4.5^{\mathrm{a}}$ & $14.8 \pm 3.7$ & $14.5 \pm 4.1$ & $12.6 \pm 2.3^{\mathrm{a}}$ \\
\hline TRACP-5b, mU/dl & $120-420$ & $323 \pm 129$ & $352 \pm 97$ & $355 \pm 123$ & $381 \pm 126$ \\
\hline $\mathrm{SOS}, \mathrm{m} / \mathrm{sec}$ & & $1,635 \pm 29$ & $1,632 \pm 24^{\mathrm{a}}$ & $1,642 \pm 24$ & $1,645 \pm 23^{\mathrm{a}}$ \\
\hline $\mathrm{TI}$ & & $1.283 \pm 0.117$ & $1.307 \pm 0.127$ & $1.259 \pm 0.089$ & $1.287 \pm 0.115$ \\
\hline OSI, & & $3.438 \pm 0.397$ & $3.492 \pm 0.421$ & $3.398 \pm 0.316$ & $3.487 \pm 0.377$ \\
\hline
\end{tabular}

${ }^{\mathrm{a}-\mathrm{c}}$ Mean values with the same superscript for the same parameter are significantly different from each other $(\mathrm{P}<0.05)$. $\mathrm{SD}$, standard deviation; 25-OH-VD, 25-hydroxyvitamin D; PTH, parathyroid hormone; Ca, calcium; BAP, bone alkaline phosphatase; TRACP-5b, tartrate-resistant acid phosphatase-5b; SOS, speed of sound; TI, transmission index; OSI, osteo-sono-assessment index.

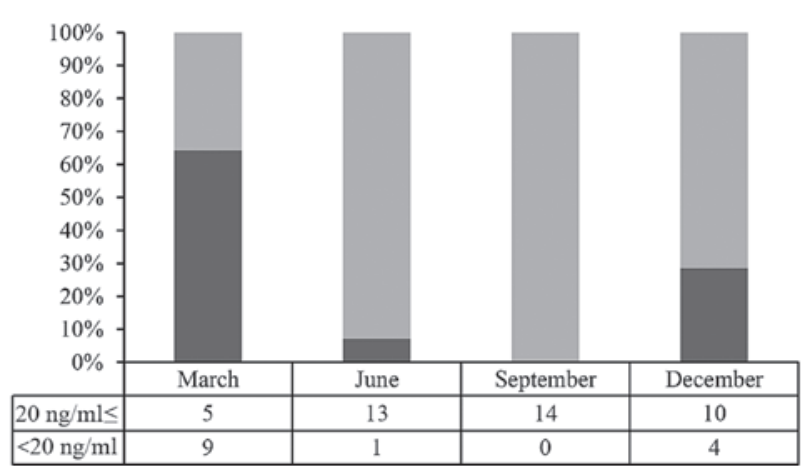

Figure 1. Proportion of 25-hydroxyvitamin D in the indoor sports athletes during the different seasons.

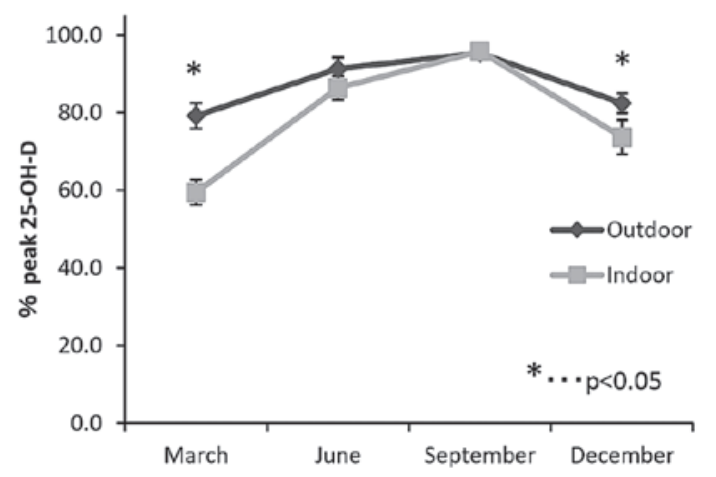

Figure 2. Percentage of peak 25-hydroxyvitamin D (25-OH-D) during the different seasons. *Outdoor vs. indoor; $\mathrm{P}<0.05$ (Mann-Whitney). Values are mean \pm standard error of the mean.

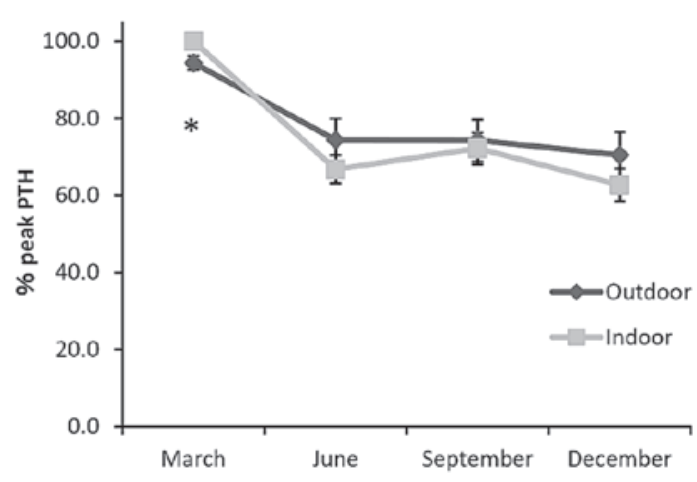

Figure 3. Percentage of peak parathyroid hormone (PTH) during the different seasons. "Outdoor vs. indoor; $\mathrm{P}<0.05$ (Mann-Whitney). Values are mean \pm standard error of the mean.

highest in March in the two groups, and that among indoor athletes (100\%) was significantly higher compared to the outdoor athletes $(94.4 \pm 6.4 \%)$ (Fig. 3).

Changes in SOS and BAP. The nadir in SOS occurred in June after the peak in December for the indoor and outdoor athletes, following 3 months after changes in 25-OH-VD $(1,632 \pm 24 \mathrm{~m} / \mathrm{sec}$ and $1,621 \pm 21 \mathrm{~m} / \mathrm{sec}$ in June; $1,645 \pm 23 \mathrm{~m} / \mathrm{sec}$ and $1,639 \pm 31 \mathrm{~m} / \mathrm{sec}$ in December, respectively). Maximum BAP was recorded in March, and decreased continuously with time toward December in the two groups $(15.4 \pm 4.5 \mu \mathrm{g} / \mathrm{l}$ and $14.7 \pm 4.5 \mu \mathrm{g} / 1$ in March; $12.6 \pm 2.3 \mu \mathrm{g} / 1$ and $12.4 \pm 3.0 \mu \mathrm{g} / 1$ in December, respectively) (Table II). 


\section{Discussion}

In the present study, the mean serum 25-OH-VD concentrations at the lowest point in winter were 19 and $32 \mathrm{ng} / \mathrm{ml}$ in the indoor and outdoor athletes, respectively. Nakamura et al (3) reported that the mean 25-OH-VD concentration in college women was $34.2 \mathrm{nmol} / 1(13.6 \mathrm{ng} / \mathrm{ml})$, and $40 \%$ of the women assessed had concentrations $<30 \mathrm{nmol} / \mathrm{l}(12 \mathrm{ng} / \mathrm{ml})$ in April. Ohta et al (8) also reported that the mean 25-OH-VD concentration was $18.7 \mathrm{ng} / \mathrm{ml}$ in Japanese female nursing students between 19 and 25 years old. The mean $25-\mathrm{OH}-\mathrm{VD}$ concentration was higher in the present study compared to the aforementioned studies investigating Japanese females of similar ages. Such discrepancies could be explained by differences in the levels of physical activity between subjects. The serum 25-OH-VD level has been reported to correlate with physical activity, such as the mean number of steps taken per day and the mean time spent sedentary (8). Dong et al (14) identified positive associations between 25-OH-VD levels and vigorous physical activity in 559 adolescents (14-18 years old). The 25-OH-VD levels in the present athletes were considered to be higher than those in non-athletes in the previous studies.

However, VD insufficiency in athletes has been reported. Hamilton et al (15) reported that $91 \%$ of 93 athletes in the Middle East showed VD deficiency or insufficiency. Lovell (9) also reported VD insufficiency in 33\% of Australian female gymnasts. In the present study, 25-OH-VD levels in 9 of 27 athletes (33\%) were less than the borderline insufficiency at $20 \mathrm{ng} / \mathrm{ml}$. These results demonstrated that VD deficiency/insufficiency represents a profound issue even in athletes.

During winter to summer, the mean levels of 25-OH-VD in the indoor athletes $(19-29 \mathrm{ng} / \mathrm{ml})$ were lower than the mean level $(30.5 \mathrm{ng} / \mathrm{ml})$ observed in athletes belonging to the National Collegiate Athletic Association (NCAA) in winter (12). Differences in gender could account for this, as subjects in the NCAA study contained male athletes, whereas the 25-OH-VD level was consistently higher in males compared to in females (16). VD intake could be another reason. In the United States, the majority of commercial milk is fortified with VD (17). By contrast, few foods are fortified in Japan, and the intake of fish, as a good source of VD, is decreasing (18). According to the 2012 National Health and Nutrition Survey Japan, the mean VD intake was $5.5 \mu \mathrm{g} /$ day in Japanese women between 18 and 29 years old (19). By contrast, Halliday et al (12) reported VD intake in NCAA athletes was $14.3 \mu \mathrm{g} / \mathrm{day}$, including supplements. VD supplementation could easily be encouraged among Japanese athletes, as dietary sources are limited.

VD status among athletes is also affected by the season and the training environment. Peeling et al (20) found that 25-OH-VD levels in an indoor young athletic group were significantly lower compared to those recorded in outdoor and mixed environments. Halliday et al (12) reported that the VD status among indoor athletes was significantly lower compared to outdoor athletes in the autumn, from September to October, and indoor athletes were susceptible to VD insufficiency in winter. The present study showed that the VD status in Japanese female indoor athletes was lower all year round compared to outdoor athletes. In particular, significant proportions of indoor athletes showed VD insufficiency during winter and autumn season.

The length of solar exposure required to synthesize $5.5 \mu \mathrm{g}$ of VD in the middle of Japan was reported as $20 \mathrm{~min}$ at any time of the day in summer and early autumn (May to September), but $>1 \mathrm{~h}$ in the morning/evening from November to March (21). The middle of Japan, in the report to estimate solar exposure (21), was within $50 \mathrm{~km}$ from the campus conducting the present study. Thus, a similar estimation should be applicable to the present subjects. As the subjects belonged to athletic clubs, solar exposure other than at training was extremely short. The absence of VD insufficiency among outdoor athletes is presumably attributable to solar exposure.

Seasonal PTH and Ca variations showed opposite but consistent patterns in the two groups, with amplitude greater in the indoor compared to the outdoor athletes. The discrepancies in PTH and Ca variations and amplitude of the variation are likely to be due to the variation of VD status, as low 25-OH-VD levels stimulated PTH secretion via low Ca levels. Gannagé-Yared et al (22) reported a positive correlation between serum 25-OH-VD concentration and $\mathrm{Ca}$ in adults between 30 and 50 years old in Lebanon, which is a country with a high sun exposure. Ono et al (11) reported that serum 25-OH-VD concentrations correlated negatively with intact PTH in a normal Japanese population between 20 and 68 years old.

By contrast, Halliday et al (12) reported that PTH concentration in athletes did not correlate with 25-OH-VD concentration at any time point or under any training environment. The present PTH pattern was also not as apparent as that of 25-OH-VD. Takada et al (23) found that PTH excretion was suppressed by moderate exercise, but was elevated consecutively by an intensive amount of training in 12 female high school basketball players. Routine training could thus reduce the amplitude of seasonal variation in PTH. The mean 25-OH-VD levels in the study by Halliday et al (12) were higher than the present study at any corresponding season. This could signify an association between $25-\mathrm{OH}-\mathrm{VD}, \mathrm{Ca}$ and PTH, particularly in indoor athletes.

The levels of the bone formation marker BAP in outdoor athletes were higher in winter compared to the summer-autumn season, and the levels in indoor athletes were higher in the winter-spring season compared to in autumn. SOS indicating bone mass was higher in autumn compared to in spring for the indoor and outdoor athletes. Pasco et al (24) reported seasonal variations in UV exposure, 25-OH-VD, PTH, bone mineral markers and BMD in 287 elderly Australian women. Peak UV exposure preceded 25-OH-VD elevation by 1 month. PTH decreased 1 month after the 25-OH-VD peak. Changes in the bone absorption marker C-terminal telopeptide of type I collagen occurred 1-2 months later, but no change was observed in BAP or BMD (24). Seasonal variations were not as apparent in the present study as in previous studies. Bone biomarker levels were affected by active bone formation, as subjects were 20-22 years old, which is around the age of peak BMD.

The importance of sun exposure has been indicated in the present study. However, solar exposure or factors such as usage of sunscreen were not explicitly examined. Further investigation is required to clarify these influences. 


\section{Acknowledgements}

The present study was supported by the JSPS Grant-in-Aid for Young Scientists (B) (grant no. 24700626) and the Ministry of Education, Culture, Sports, Science and the Technology-Supported Program for the Strategic Research Foundation at Private Universities.

\section{References}

1. Orito S, Kuroda T, Onoe Y, Sato Y and Ohta H: Age-related distribution of bone and skeletal parameters in 1,322 Japanese young women. J Bone Miner Metab 27: 698-704, 2009.

2. Mithal A, Wahl DA, Bonjour JP, Burckhardt P, Dawson-Hughes B, Eisman JA, El-Hajj Fuleihan G, Josse RG, Lips P and Morales-Torres J; IOF Committee of Scientific Advisors (CSA) Nutrition Working Group: Global vitamin D status and determinants of hypovitaminosis D. Osteoporos Int 20: 1807-1820, 2009.

3. Nakamura K, Nashimoto M, Tsuchiya Y, Obata A, Miyanishi K and Yamamoto M: Vitamin D insufficiency in Japanese female college students: A preliminary report. Int J Vitam Nutr Res 71: 302-305, 2001

4. Nakamura K, Nashimoto M, Matsuyama S and Yamamoto M: Low serum concentrations of 25-hydroxyvitamin D in young adult Japanese women: A cross sectional study. Nutrition 17: 921-925, 2001

5. Foo LH, Zhang Q, Zhu K, Ma G, Trube A, Greenfield H and Fraser DR: Relationship between vitamin D status, body composition and physical exercise of adolescent girls in Beijing Osteoporos Int 20: 417-425, 2009.

6. Courteix D, Lespessailles E, Peres SL, Obert P, Germain P and Benhamou CL: Effect of physical training on bone mineral density in prepubertal girls: A comparative study between impact-loading and non-impact-loading sports. Osteoporos Int 8: 152-158, 1998.

7. Creighton DL, Morgan AL, Boardley D and Brolinson PG: Weight-bearing exercise and markers of bone turnover in female athletes. J Appl Physiol (1985) 90: 565-570, 2001.

8. Ohta H, Kuroda T, Onoe Y, Orito S, Ohara M, Kume M, Harada A, Tsugawa N, Okano T and Sasaki S: The impact of lifestyle factors on serum 25-hydroxyvitamin D levels: A cross-sectional study in Japanese women aged 19-25 years. J Bone Miner Metab 27: 682-688, 2009

9. Lovell G: Vitamin D status of females in an elite gymnastics program. Clin J Sport Med 18: 159-161, 2008.

10. Constantini NW, Arieli R, Chodick G and Dubnov-Raz G: High prevalence of vitamin D insufficiency in athletes and dancers. Clin J Sport Med 20: 368-371, 2010.

11. Ono Y, Suzuki A, Kotake M, Zhang X, Nishiwaki-Yasuda K, Ishiwata Y, Imamura S, Nagata M, Takamoto S and Itoh M: Seasonal changes of serum 25-hydroxyvitamin D and intact parathyroid hormone levels in a normal Japanese population. J Bone Miner Metab 23: 147-151, 2005.
12. Halliday TM, Peterson NJ, Thomas JJ, Kleppinger K, Hollis BW and Larson-Meyer DE: Vitamin D status relative to diet, lifestyle, injury, and illness in college athletes. Med Sci Sports Exerc 43: 335-343, 2011.

13. Sasaki M, Harata S, Kumazawa Y, Mita R, Kida K and Tsuge M: Bone mineral density and osteo sono assessment index in adolescents. J Orthop Sci 5: 185-191, 2000.

14. Dong Y, Pollock N, Stallmann-Jorgensen IS, Gutin B, Lan L, Chen TC, Keeton D, Petty K, Holick MF and Zhu H: Low 25-hydroxyvitamin D levels in adolescents: Race, season, adiposity, physical activity, and fitness. Pediatrics 125: 1104-1111, 2010.

15. Hamilton B, Grantham J, Racinais S and Chalabi H: Vitamin D deficiency is endemic in Middle Eastern sportsmen. Public Health Nutr 13: 1528-1534, 2010.

16. Bolland MJ, Grey AB, Ames RW, Mason BH, Horne AM, Gamble GD and Reid IR: The effects of seasonal variation of 25-hydroxyvitamin D and fat mass on a diagnosis of vitamin D sufficiency. Am J Clin Nutr 86: 959-964, 2007.

17. Patterson KY, Phillips KM, Horst RL, Byrdwell WC, Exler J, Lemar LE and Holden JM: Vitamin D content and variability in fluid milks from a US Department of Agriculture nationwide sampling to update values in the National Nutrient Database for Standard Reference. J Dairy Sci 93: 5082-5090, 2010.

18. Ministry of Agriculture, Forestry and Fisheries: Fisheries of Japan-FY2011 (2011/2012) Fisheries Policy Outline for FY2012 (White Paper on Fisheries: Summary). http://www.jfa.maff. go.jp/j/kikaku/wpaper/pdf/2011_jfa_wp.pdf.

19. Ministry of Health: Labour and Welfare: The National Health and Nutrition Survey in Japan, 2012 (In Japanese). http://www. mhlw.go.jp/bunya/kenkou/eiyou/dl/h24-houkoku.pdf. 2014.

20. Peeling P, Fulton SK, Binnie M and Goodman C: Training environment and Vitamin D status in athletes. Int J Sports Med 34: 248-252, 2013

21. Miyauchi $M$, Hirai $C$ and Nakajima $H$ : The solar exposure time required for vitamin D3 synthesis in the human body estimated by numerical simulation and observation in Japan. J Nutr Sci Vitaminol (Tokyo) 59: 257-263, 2013.

22. Gannagé-Yared MH, Chemali R, Yaacoub N and Halaby G: Hypovitaminosis D in a sunny country: Relation to lifestyle and bone markers. J Bone Miner Res 15: 1856-1862, 2000.

23. Takada H, Washino K, Hanai $\mathrm{T}$ and Iwata H: Response of parathyroid hormone to exercise and bone mineral density in adolescent female athletes. Environ Health Prev Med 2: 161-166, 1998.

24. Pasco JA, Henry MJ, Kotowicz MA, Sanders KM, Seeman E, Pasco JR, Schneider HG and Nicholson GC: Seasonal periodicity of serum vitamin D and parathyroid hormone, bone resorption, and fractures: The Geelong Osteoporosis Study. J Bone Miner Res 19: 752-758, 2004. 